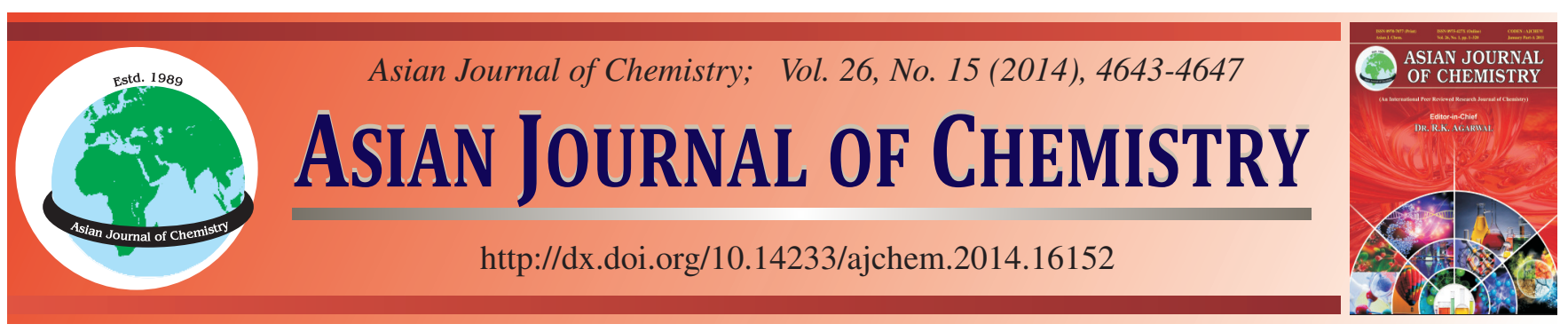

\title{
Antiinflammatory and Analgesic Activities of Different Fractions of Populus tomentosa Carr. Leaves
}

Xueyan Fu*, Tingting Li , Baitong Zhang, Xinhui Zhang, Lin Dong, Xueqin Ma, Jing Chen and Luping Qin

Pharmacy College, Ningxia Medical University, Yinchuan 750003, P.R. China

*Corresponding author: Fax: +86 21 64085875; Tel: +86 13469502661; E-mail: fuxueyan1215@yahoo.com.cn

The antiinflammatory and analgesic properties of different polar fractions of Populus tomentosa leaves were investigated in mice. The analgesic activities of leaf extracts were evaluated with hot-plate and acetic acid writhing tests. Anti-inflammatory effects were studied using xylene-induced ear edema and egg albumen-induced paw edema. Low dose $(1 \mathrm{~g} / \mathrm{kg})$ and high dose $(3 \mathrm{~g} / \mathrm{kg})$ aqueous extracts had significant analgesic effects $(\mathrm{p}<0.05)$ for the acetic acid writhing test. High doses of ethanol $(3 \mathrm{~g} / \mathrm{kg})$, petroleum ether $(0.5 \mathrm{~g} / \mathrm{kg})$ and butanol extracts $(0.5 \mathrm{~g} / \mathrm{kg})$ prolonged hot-plate reaction times $(\mathrm{p}<0.05)$ and had better analgesia. Petroleum ether extract $(0.5 \mathrm{~g} / \mathrm{kg}) \mathrm{was}$ better than controls for reducing xylene-induced ear edema $(\mathrm{p}<0.05)$. Low doses of aqueous $(1 \mathrm{~g} / \mathrm{kg})$, ethyl acetate $(0.5 \mathrm{~g} / \mathrm{kg})$ and butanol extracts $(0.5 \mathrm{~g} / \mathrm{kg})$ reduced foot swelling due to egg albumen better than controls $(\mathrm{p}<0.05)$. These findings indicate that water and ethanol extracts, as well as different ethanol polarity fractions, from Populus tomentosa leaves have analgesic and anti-inflammatory effects which are consistent with their use in traditional medicine.

Keywords: Populus tomentosa leaves, Screening, Active fraction, Antiinflammatory, Analgesic.

\section{INTRODUCTION}

Populus tomentosa Carr. belongs to Salicales family and is mainly distributed in Ningxia, Neimenggu and western China. Populus tomentosa leaves are widely used folk medicine remedies in western China for treating soft tissue infections and suppurative osteomyelitis ${ }^{1}$, trauma, scald, carbuncle and soreness. Populus tomentos leaves were used for treating dysentery in the compendium of materia medica. Populus tomentosa leaves have expectorant, bacteriostatic, antipyretic and analgesic properties ${ }^{2}$. The flowers of Populus tomentosa have recovery rates of $77 \%$ for treatment of acute bacillary dysentery ${ }^{3}$. The ethanol extract of Populus tomentosa Carr. bark has expectorant effects curative rates of $86 \%$ for decubitous ulcers ${ }^{4}$.

In recent years, there have the report in treatment of pressure ulcer using poplar leaves ${ }^{5}$ and also have the report about poplar flower and poplar bud. They study on flavonoids types and pharmacological including antiinflammatory research in poplar flower ${ }^{6}$. It is presumed that the think poplar flower has the treatment of bacillary dysentery and enteritis, at the same time it has obvious anti-tumor, antipyretic analgesic and antirheumatic effects ${ }^{7}$. The poplar flower water extract was also used to be antiinflammatory experiment ${ }^{8}$. On poplar bud, they through different polar parts of extract to do anti- oxidant and antitumor and antibacterial experiment ${ }^{9}$. but there no relevant report about the poplar leaves of different polar parts of antiinflammatory and analgesic experiments. So this research aims to study about which polar parts have good antiinflammatory and analgesic effects in poplar leaves. For poplar leaves medicinal research and development makes the theory basis and clinical guidance.

Populin and salicin are the main therapeutic components of Populus tomentosa, as they have antipyretic, analgesic and antirheumatic activities ${ }^{10}$. Folk medicine and clinical impressions are that these compounds have antiinflammatory and analgesic properties for treatment of decubital ulcer, but this has not been researched. Aqueous extracts of Populus tomentosa leaves have strong antibacterial and antiviral effects, but additional active fractions have not been identified and pharmacokinetics have not been established.

Our study evaluated the analgesic and antiinflammatory properties of Populus tomentosa leaves. Analgesic properties of extracts were evaluated with hot-plate and acetic acid writhing tests. Antiinflammatory effects were studied using xylene-induced ears edema and egg albumen-induced paw edema in mice. Our results showed that different polar fractions of Populus tomentosa leaves have antiinflammatory and analgesic effects. 
EXPERIMENTAL

Populus tomentosa leaves (identification by Xueyan Fu, Ningxia Medical University) were collected between September and October in Yinchuan suburbs. After collection, all leaves were washed three times with water to remove surface dust and debris. Washed leaves were dried outside in a shaded location.

Ethanol (95\%), xylene, glacial acetic acid (Damao Chemicals Co, Tianjin, China) dexamethasone and indomethacin, all the chemicals reagents are used as analytical reagent.

$100 \mathrm{~g}$ of Populus tomentosa leaves and $800 \mathrm{~mL}$ of water were extracted with a microwave using three 10 min cycles. The filtrate was amalgamated and suctioned, followed by evaporation to dryness with a rotary evaporation instrument. The material was then grounded into a powder, weighed and prepared to the appropriate concentration for each group. This process was duplicated with $800 \mathrm{~mL}$ of $60 \%$ ethanol. This resulted in powdered aqueous and ethanol extracts.

Petroleum ether, ethyl acetate and butyl ethanol were used with a separatory funnel to further extract leaf products from the ethanol extract of the filtrate. Each of these organic reagent extracts was colourless. After the ethanol evaporated and the product was dry, it was grounded into a powder, weighed and prepared to the appropriate concentration for each group.

Animals and experimental design: Forty-five male and 45 female mice $(20 \pm 2 \mathrm{~g})$ were used for this study. The mice were housed in the Animal Center of Ningxia Medical University with standard feed (Keaoxieli Feeds Ltd, Beijing) and environmental conditions (ambient room temperature 25 $\pm 2{ }^{\circ} \mathrm{C}$ and $12 \mathrm{~h}$ light-dark cycle) and clean water ad libitum. After 3 days, mice were randomly divided into nine groups, each consisting of ten mice with an equal sex ratio: blank group (physiological saline, $20 \mathrm{~mL} / \mathrm{kg}$ ); positive control group (indomethacin $1 \mathrm{mg} / \mathrm{kg}$ ); low dose water extraction group (1 $\mathrm{g} / \mathrm{kg}$ ), high dose water extraction group (3 $\mathrm{g} / \mathrm{kg})$; low dose ethanol extraction group $(1 \mathrm{~g} / \mathrm{kg})$; high dose ethanol extraction group $(3 \mathrm{~g} / \mathrm{kg})$; petroleum ether extract group $(0.5 \mathrm{~g} / \mathrm{kg})$; ethyl acetate extract group $(0.5 \mathrm{~g} / \mathrm{kg})$; butanol extract group $(0.5$ $\mathrm{g} / \mathrm{kg}$ ). Mice were gavaged with $0.2 \mathrm{~m} \mathrm{~L} / 10 \mathrm{~g}$ for each treatment group.

Acetic acid induced writhing response in mice (Fig. 1): After $1 \mathrm{~h}$, each mouse was gastric lavaged with the dose for its treatment group, it received an intraperitoneal injection of acetic acid $(0.6 \%)(1 \mathrm{~mL} / \mathrm{kg}$ of body weight). Mice were then placed in a transparent box and the time of writhing movement was recorded ${ }^{11}$.

Swelling inhibition rate $(\%)=($ the average degree of swelling for the control group - treatment group's average degree of swelling)/(the control group's average degree of swelling) $\times 100 \%^{12}$.

Hot plate reaction time in mice (Fig. 2): The hot plate reaction time was recorded as the time from when a mouse's foot contacts the hot plate $\left(56 \pm 0.5{ }^{\circ} \mathrm{C}\right)$ until licking of the foot (pain threshold, latency) occurs. Pain latencies of mice that were greater than 60 s or less than $5 \mathrm{~s}$ were eliminated ${ }^{13}$. In order to avoid scalding the mice, experiments were terminated if there were no paw lick responses by $60 \mathrm{~s}$. Experiments were conducted at room temperature $\left(18{ }^{\circ} \mathrm{C}\right)$. The experiment was repeated 3 times.

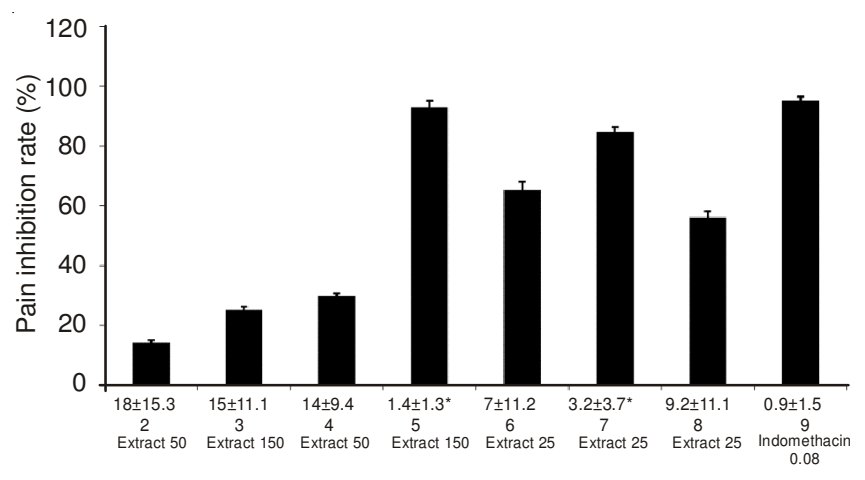

Fig. 1. Values are expressed in mean $\pm \mathrm{SD}(\mathrm{n}=10) . * \mathrm{P}<0.05$, statistically significant compared with1. (2 is low dose group of water extraction, 3 is high dose group of water extraction, 4 is low dose group of ethanol extraction, 5 is high dose group of ethanol extraction, 6 is group of Petroleum ether extract, 7 is group of Ethyl acetate extract, 8 is group of Ethyl acetate extract, 9 is positive control)

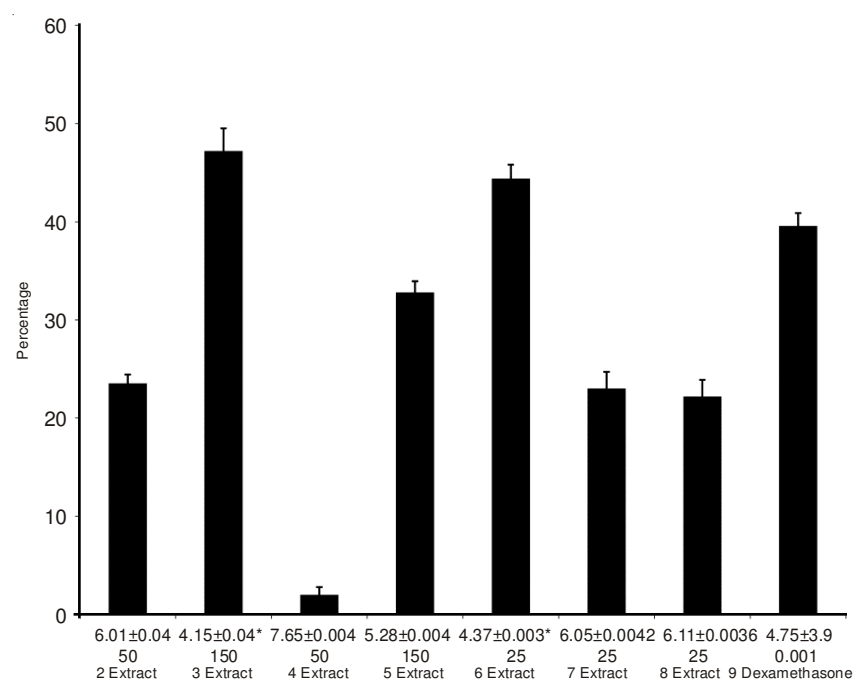

Fig. 2. Each value is mean $\pm \mathrm{SD}(\mathrm{n}=10) ; * \mathrm{P}<0.05$, statistically significant compared with the treated control (normal saline). ( 2 is low dose group of water extraction, 3 is high dose group of water extraction, 4 is low dose group of ethanol extraction, 5 is high dose group of ethanol extraction, 6 is group of petroleum ether extract, 7 is group of ethyl acetate extract, 8 is group of ethyl acetate extract, 9 is positive control)

Swelling inhibition rate $(\%)=($ the control group's average degree of swelling - the treatment group's average degree of swelling)/(the control group's average degree of swelling) $\times$ $100 \%{ }^{12}$.

Egg albumen causes foot swelling in mice (Fig. 3): Nine groups of 10 mice each were fasted for $12 \mathrm{~h}$ before the experiment. The extract and standard for group were prepared and administered via gastric lavage. After $1 \mathrm{~h}, 0.1 \mathrm{~mL}$ fresh egg albumen was injected to the lateral mallelolus on the sub plantar region of the right hind paw of the mice, with the left foot serving as a control. The mice were sacrificed after 4 min and the paws were removed and weighed with an analytical balance designed to weigh the foot. The percentage inhibition of inflammation was calculated based on comparisons of the right and left feet. The ratio of the anti-inflammatory effect was calculated by the following equation: Swelling inhibition rate $(\%)=($ the control group's average degree of swellingtreatment group's average degree of swelling)/(the control group's average degree of swelling) $\times 100 \%$. 


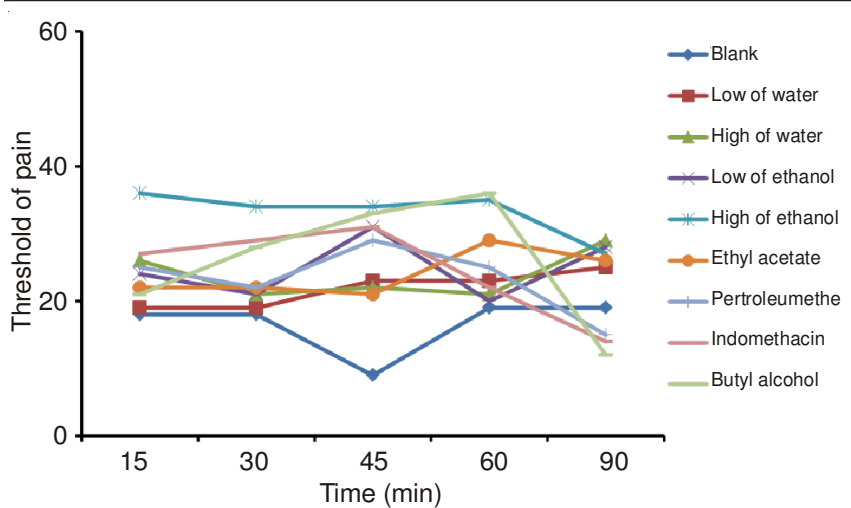

Fig. 3. Each value is mean \pm SEM of 10 mice; $* \mathrm{P}<0.05$, statistically significant compared with the treated control (normal saline). ( 2 is low dose group of water extraction, 3 is high dose group of water extraction, 4 is low dose group of ethanol extraction, 5 is high dose group of ethanol extraction, 6 is group of petroleum ether extract, 7 is group of ethyl acetate extract, 8 is group of ethyl acetate extract, 9 is positive control)

Ear-swelling due to xylene in mice (Fig. 4): Nine groups of 10 mice each were fasted for $12 \mathrm{~h}$ before the experiment. Each mouse was lavaged extract as specified for its assigned treatment group. After $1 \mathrm{~h}$, ear edema was induced by topically administering xylene, Mice were sacrificed after $40 \mathrm{~min}$ and ears were removed and weighed on an analytical balance designed for this purpose. The percentage of inflammation inhibition was calculated by comparing right and left ears. The ratio of the anti-inflammatory effect was calculated with the following equation: Swelling inhibition rate $(\%)=($ the control group's average degree of swelling - treatment group's average degree of swelling)/(the control group's the average degree of swelling) $\times 100 \%{ }^{12}$.

Statistical analysis: All analyses were conducted using SPSS 11.5 (company, location. Data are reported as the mean $\pm \mathrm{SD}$ for ten replicates. One-way analysis of variance (ANOVA) was performed. Means were separated with Duncan multiple range tests using and complemented with student's $t$-test. Values were considered statistically significant at $\mathrm{p}<$ 0.05 .

\section{RESULTS AND DISCUSSION}

Analgesic activities of different Populus tomentosa Carr. leaf fractions: Inhibitory rates of the high dose ethanol and

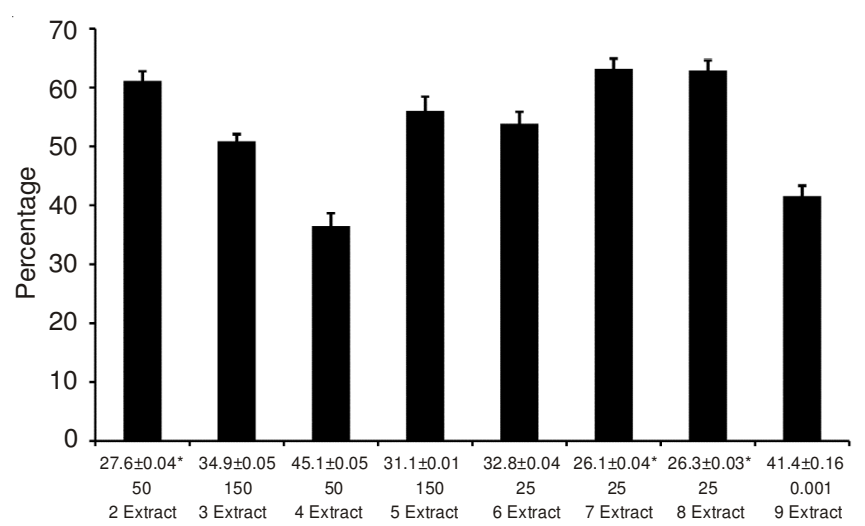

Fig. 4. Each value is mean $\pm \mathrm{SD}$ of 10 mice; $* \mathrm{P}<0.05$, statistically significant compared with the treated control (normal saline). ( 2 is low dose group of water extraction, 3 is high dose group of water extraction, 4 is low dose group of ethanol extraction, 5 is high dose group of ethanol extraction, 6 is group of petroleum ether extract, 7 is group of ethyl acetate extract, 8 is group of ethyl acetate extract, 9 is positive control)

ethyl acetate leaf extracts on the writhing response in mice were 93 and $84.7 \%$, respectively (Table-1). Pain inhibition from Populus tomentosa leaf extracts varied with time, with a peak at $45 \mathrm{~min}$ and subsequent declines with time. The best analgesic effects were observed for high ethanol, petroleum ether and butanol extracts(Table-2).

Antiinflammatory activity of different Populus tomentosa Carr. leaf fractions: Sub-acute inflammation testing using the egg albumen-induced inflammatory model demonstrated that inhibition of paw oedema was dose dependent for all extracts and all extracts suppressed inflammation more than the positive control drug except for the number 4 extract. These extracts significantly reduced the weights of feet injected with egg albumen (Table-3). Only group 3 and group 6 extracts significantly reduced the weight (reduced ear swelling) of ears exposed to xylene compared to the positive control drug; the remaining groups had no significant effects (Table-4).

The antiinflammatory effects of Populus tomentosa leaves on xylene-induced ear-swelling in mice are not significant, but the extract groups reduced ear-swelling compared to blank controls. Number 3 group and number 6 group had greater effects than the positive control for High dose ethanol and ethyl acetate extracts reduced the acetic acid-induced writhing response compared to blank and positive controls. The hot plate reaction times for mice were longer for the high dose

\begin{tabular}{|c|c|c|c|c|}
\hline \multicolumn{5}{|c|}{$\begin{array}{c}\text { TABLE-1 } \\
\text { EFFECT OF Populus tomentosa LEAF EXTRACT ON ACETIC ACID-INDUCED WRITHING RESPONSE IN MICE }\end{array}$} \\
\hline & Treatment & Dose $(\mathrm{g} / \mathrm{kg})$ & Mean \pm SEM of abdominal constrictions & Inhibition (\%) \\
\hline 1 & Control & - & $21 \pm 10.3$ & - \\
\hline 2 & Extract & 50 & $18 \pm 15.3$ & 14.2 \\
\hline 3 & Extract & 150 & $15 \pm 11.1$ & 25.2 \\
\hline 4 & Extract & 50 & $14 \pm 9.4$ & 29.7 \\
\hline 5 & Extract & 150 & $1.4 \pm 1.3^{*}$ & 93 \\
\hline 6 & Extract & 25 & $7 \pm 11.2$ & 65.2 \\
\hline 7 & Extract & 25 & $3.2 \pm 3.7 *$ & 84.7 \\
\hline 8 & Extract & 25 & $9.2 \pm 11.1$ & 56.1 \\
\hline 9 & Indomethacin & 0.08 & $0.9 \pm 1.5$ & 95.23 \\
\hline
\end{tabular}




\begin{tabular}{|c|c|c|c|c|c|c|c|}
\hline \multicolumn{8}{|c|}{$\begin{array}{c}\text { TABLE-2 } \\
\text { ANALGESIC ACTIVITY OF Populus tomentosa LEAF EXTRACT WITH HOT PLATE TESTING }\end{array}$} \\
\hline & \multirow{2}{*}{ Treatment } & \multirow{2}{*}{ Dose (g/kg) } & \multicolumn{5}{|c|}{ Reaction Time (sec) } \\
\hline & & & $15(\min )$ & $30(\mathrm{~min})$ & $45(\min )$ & $60(\min )$ & $90(\mathrm{~min})$ \\
\hline 1 & Control & - & $18 \pm 3$ & $18 \pm 4$ & $9 \pm 1$ & $19 \pm 3$ & $19 \pm 8$ \\
\hline 2 & Extract & 50 & $19 \pm 5$ & $19 \pm 5$ & $23 \pm 12$ & $23 \pm 7$ & $25 \pm 14$ \\
\hline 3 & Extract & 150 & $26 \pm 10$ & $21 \pm 6$ & $22 \pm 9$ & $21 \pm 8$ & $29 \pm 13$ \\
\hline 4 & Extract & 50 & $24 \pm 8$ & $21 \pm 8$ & $31 \pm 13$ & $20 \pm 7$ & $28 \pm 12$ \\
\hline 5 & Extract & 150 & $36 \pm 19$ & $34 \pm 15$ & $34 \pm 15^{*}$ & $35 \pm 14$ & $27 \pm 17$ \\
\hline 6 & Extract & 25 & $22 \pm 14$ & $22 \pm 10$ & $21 \pm 9 *$ & $29 \pm 12$ & $26 \pm 11$ \\
\hline 7 & Extract & 25 & $25 \pm 8$ & $22 \pm 7$ & $29 \pm 10$ & $25 \pm 6$ & $31 \pm 15$ \\
\hline 8 & Extract & 25 & $27 \pm 12$ & $29 \pm 15$ & $31 \pm 12^{*}$ & $22 \pm 7$ & $29 \pm 14$ \\
\hline 9 & Indomethacin & 0.08 & $21 \pm 5$ & $28 \pm 7$ & $33 \pm 6$ & $36 \pm 13$ & $34 \pm 12$ \\
\hline
\end{tabular}

Note: Each value is mean \pm standard deviation $(\mathrm{n}=10)$; $* \mathrm{P}<0.05$, statistically significant compared with the treated control (normal saline). ( 2 is low dose group of water extraction, 3 is high dose group of water extraction, 4 is low dose group of ethanol extraction, 5 is high dose group of ethanol extraction, 6 is group of Petroleum ether extract, 7 is group of Ethyl acetate extract, 8 is group of Ethyl acetate extract, 9 is positive control)

\begin{tabular}{|c|c|c|c|c|}
\hline & \multicolumn{3}{|c|}{$\begin{array}{l}\text { TABLE-3 } \\
\text { ANTI-INFLAMMATORY ACTIVITY OF Populus tomentosa LEAF EXTRACTS } \\
\text { ON TOE SWELLING IN MICE INJECTED WITH EGG ALBUMEN }\end{array}$} & \multirow[b]{2}{*}{ Inhibition (\%) } \\
\hline & Treatment & Dose $(\mathrm{g} / \mathrm{kg})$ & Degree of swelling (mg) & \\
\hline 1 & Control & - & $71.1 \pm 0.11$ & ----- \\
\hline 2 & Extract & 50 & $27.6 \pm 0.04 *$ & 61.1 \\
\hline 3 & Extract & 150 & $34.9 \pm 0.05$ & 50.8 \\
\hline 4 & Extract & 50 & $45.1 \pm 0.05$ & 36.4 \\
\hline 5 & Extract & 150 & $31.1 \pm 0.01$ & 56.1 \\
\hline 6 & Extract & 25 & $32.8 \pm 0.04$ & 53.8 \\
\hline 7 & Extract & 25 & $26.1 \pm 0.04 *$ & 63.2 \\
\hline 8 & Extract & 25 & $26.3 \pm 0.03^{*}$ & 62.9 \\
\hline 9 & Dexamethasone & 0.001 & $41.4 \pm 0.16$ & 41.6 \\
\hline
\end{tabular}

Each value is mean \pm SEM of 10 mice; $* \mathrm{P}<0.05$, statistically significant compared with the treated control (normal saline). ( 2 is low dose group of water extraction, 3 is high dose group of water extraction, 4 is low dose group of ethanol extraction, 5 is high dose group of ethanol extraction, 6 is group of Petroleum ether extract, 7 is group of Ethyl acetate extract, 8 is group of Ethyl acetate extract, 9 is positive control)

\begin{tabular}{lcccc}
\hline & Treatment & Dose $(\mathrm{g} / \mathrm{kg})$ & Degreeof swelling $(\mathrm{mg})$ & Inhibition $(\%)$ \\
\hline 1 & Control & - & $7.86 \pm 3.4$ & - \\
2 & Extract & 50 & $6.01 \pm 0.04$ & 23.54 \\
3 & Extract & 150 & $4.15 \pm 0.004^{*}$ & 47.2 \\
4 & Extract & 50 & $7.65 \pm 0.004$ & 2 \\
5 & Extract & 150 & $5.28 \pm 0.004$ & 32.8 \\
6 & Extract & 25 & $4.37 \pm 0.003^{*}$ & 44.4 \\
7 & Extract & 25 & $6.05 \pm 0.0042$ & 23 \\
8 & Extract & 25 & $6.11 \pm 0.0036$ & 22.2 \\
9 & Dexamethasone & 0.001 & $4.75 \pm 3.9$ & 39.57 \\
\hline
\end{tabular}

Note: Each value is mean $\pm \mathrm{SD}$ of 10 mice; $* \mathrm{P}<0.05$, statistically significant compared with the treated control (normal saline). ( 2 is low dose group of water extraction, 3 is high dose group of water extraction, 4 is low dose group of ethanol extraction, 5 is high dose group of ethanol extraction, 6 is group of Petroleum ether extract, 7 is group of Ethyl acetate extract, 8 is group of Ethyl acetate extract, 9 is positive control)

ethanol, petroleum ether and ethyl acetate extract groups than for blank and positive controls. These results demonstrate that the multiple fractions in ethanol extracts have greater antiinflammatory and analgesic activities than do aqueous extracts.

The acetic acid induced writhing test is a non-specific but sensitive method that is widely used for analgesic screening ${ }^{14}$ and is able to detect anti-nociceptive effects of compounds at dose levels that may appear inactive in other methods like tail flick test ${ }^{15}$. A $100 \%$ inhibition of writhing was evident in the animals at both doses of the extract and the reference drug in this study. The hot plate test is the most common test of nociception and it is based on a phasic stimulus of high intensity ${ }^{16}$. Pain induced by thermal stimulus of the hot plate is specific for centrally mediated nociception ${ }^{17}$. The ability of the extract to prolong the reaction latency to pain thermallyinduced in mice by the hot plate further suggests central analgesic activity.

Populus tomentosa leaf extracts have anti-inflammatory effects that can be attributed to tremulacin (a salicin-related substance). The mechanism of tremulacin differs from aspirin, as it inhibits the release of inflammatory mediators and also blocks these mediators from binding to their receptors.

Egg albumen-induced hind paw edema is a standard experimental model of acute inflammation. Egg albumen is the agent of choice for testing antiinflammatory drugs because it is not known to be antigenic and is devoid of apparent systemic effects. Egg albumen-induced edema is a biphasic response. The first phase is mediated through the release of histamine, 
serotonin and kinins, whereas, the second phase is the consequence of the release of prostaglandin and slow reacting substances that peak at $3 \mathrm{~h}$ following insult. The increase in paw volume following egg albumen administration in the control $(0.1 \pm 0.14 \mathrm{~mL})$ and dexamethasone treated group $(1$ $\pm 0.01 \mathrm{~mL}$ ) corresponds with the findings of previous research. The extracts reduced foot swelling more than positive controls, with ethanol extracts producing dose-dependent and significant inhibition of egg albumen-induced paw edema.

Populus tomentosa Carr. leaves grow in China but not in other foreign countries. This plant's leaves have great medicinal value that merit further research. Our study provides a theoretical base for the rational use of Populus tomentosa Carr. leaves in clinical medicine. Further research is needed and we will investigate dissociation and extraction.

\section{REFERENCES}

1. M. Lin and S.Z. Li, Yao Xue Xue Bao, 28, 437 (1993).

2. X.L. Du and F.Q. Xue, Northwest Pharm. J., 11, 86 (1996).

3. X.-Z. Yang, Inner Mongolia J. Tradit. Chinese Med., vol. 10 (1987).
4. G.Z. Li and Z.G. Tao, Shanxi J. Tradit. Chin. Med., 5, 45 (1985).

5. Family Nurse, 2006

6. Heilong jiang Animal Husbandry and Veternary Guide edition, 2012.

7. F.-W. Li, Study on Compounds of Populus Tomentosacarr, Shandong Agricultural University, Tai'an, pp. 5-6 (2005).

8. Chinese Veterinary Science, 2006.

9. Chinese Journal of Clinical Pharmacology and Therapeutics, 2012

10. T.B. Ma, M.G. Li and J.L. Li, Chin. Tradit. Herbal Drugs, 15, 9 (1957).

11. R. Koster, M. Anderson and E.J. De Beer, Acetic acid for analgesic screening. In: Federation Proceedings, p 412 (1959).

12. D.H. Dang, M.H. Hoang, M.T. Nguyen, V.M. Chau and T.T.H. Nguyen, Vietnam J. Chem., 46, 81 (2008).

13. H.G. Vogel, Drug Discovery and Evaluation, Springer (2002).

14. D. Le Bars, M. Gozariu and S.W. Cadden, Pharmacol. Rev., 53, 597 (2001).

15. G.A. Bentley, S.H. Newton and J. Starr, Br. J. Pharmacol., 73, 325 (1981).

16. A. Mandegary, M. Sayyah, M. Kamalinejad and M.R. Heidari, Daru, 12, 58 (2004)

17. J. Parkhouse and B.J. Parkhouse, Analgesics Drugs. Blackwell Co, Traditional Chinese Herbal Medicine of Information Center of the State Administration, Handbook of Plant Effective Constituent. People's Health Publishing House, Beijing (1979). 